\title{
THE DISCOVERY OF ECLIMUS HARRISI IN THE WHITE MOUNTAINS, N. H.
}

\author{
By Charles W. Johnson, \\ Boston Society of Natural History.
}

This interesting species has long been known only by the type, a male, in the Harris collection, in the Boston Society of Natural History. It bears the label, "H. Gray," without date or locality. It was described by Osten Sacken as Epibates harrisi in his Western Diptera (Bull. U. S. Geol. Survey, Vol. 3, p. 273, 1877). In the note following the description he says: "It is probably from the Northern United States as are nearly all the specimens in the collection." On page 271 in the table of species it is referred doubtfully to the "Atlantic States (?)," but in the table of contents where all the species are arranged systematically with localities, "Massachusetts" is given without a question. I am unable to find any authority for this and doubt if Osten Sacken made the table of contents.

During the meeting of the New England Federation of Natural History Societies at the Glen House the first week in July, frequent collecting trips were made to various parts of the mountains. On July 8, I captured a male of Eclimus harrisi on the flowers of the blackberry on the Mount Washington Road near the Raymond trail, just below the two-mile post, at an elevation of about 2,600 feet. This resembles the type in every respect except that its length is $12 \mathrm{~mm}$. while the type measures $14 \mathrm{~mm}$. A female of this species wa; taken by Mr. C. A. Frost, July 6, along the railway, above Base Station.

\section{A REVIEW OF OUR SPECIES OF TRIGONOMETOPUS}

(DIPTERA; LAUXANIIDE).

By Frederick Knab, Bureau of Entomology, Washington, D. C.

The Lauxaniid genus Trigonometopus is easily recognizable by the peculiar shape of the elongate head, triangular in profile, with the frons horizontal and the face strongly receding, the antennæ nserted at the apex of the triangle. Four species have been 

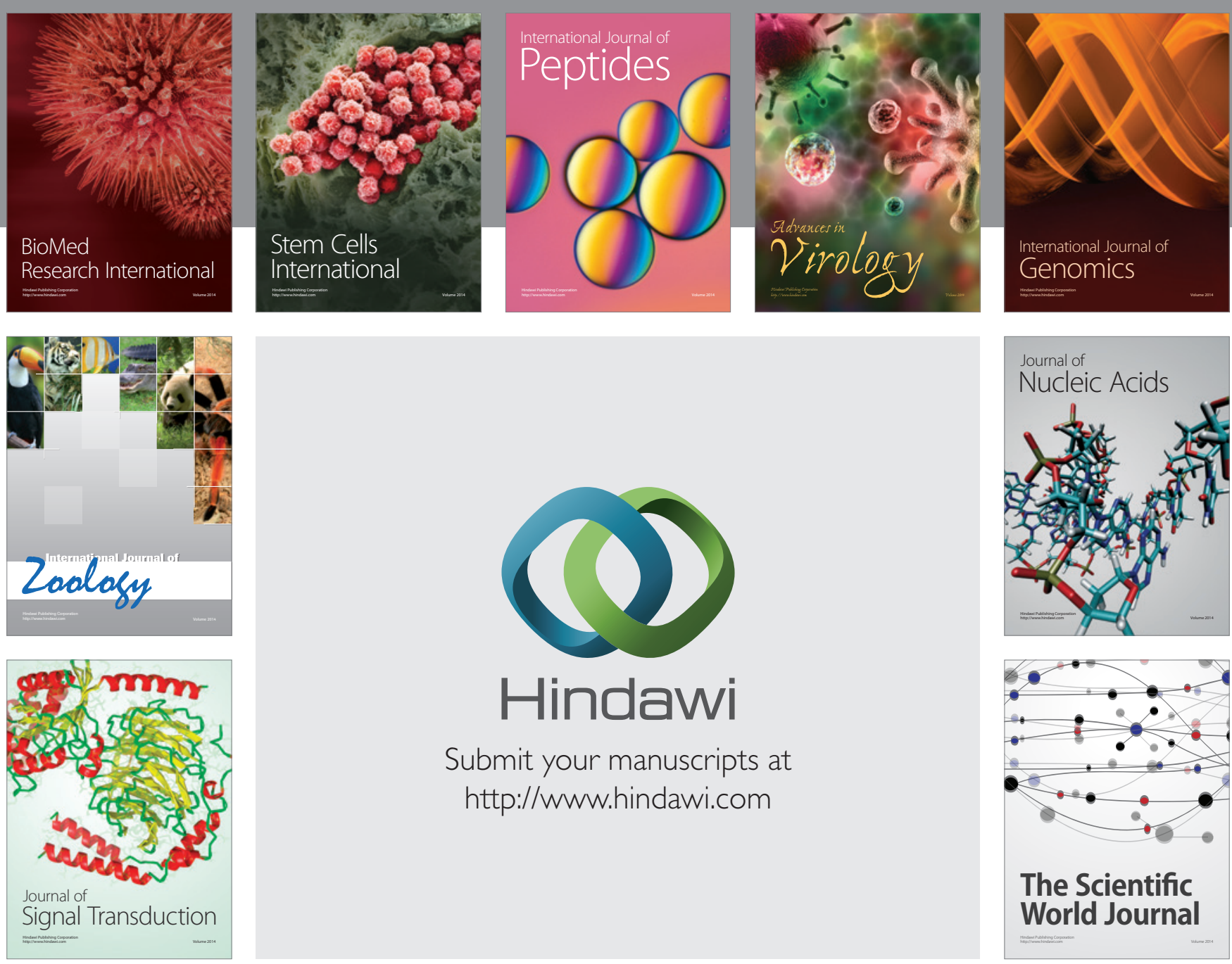

Submit your manuscripts at

http://www.hindawi.com
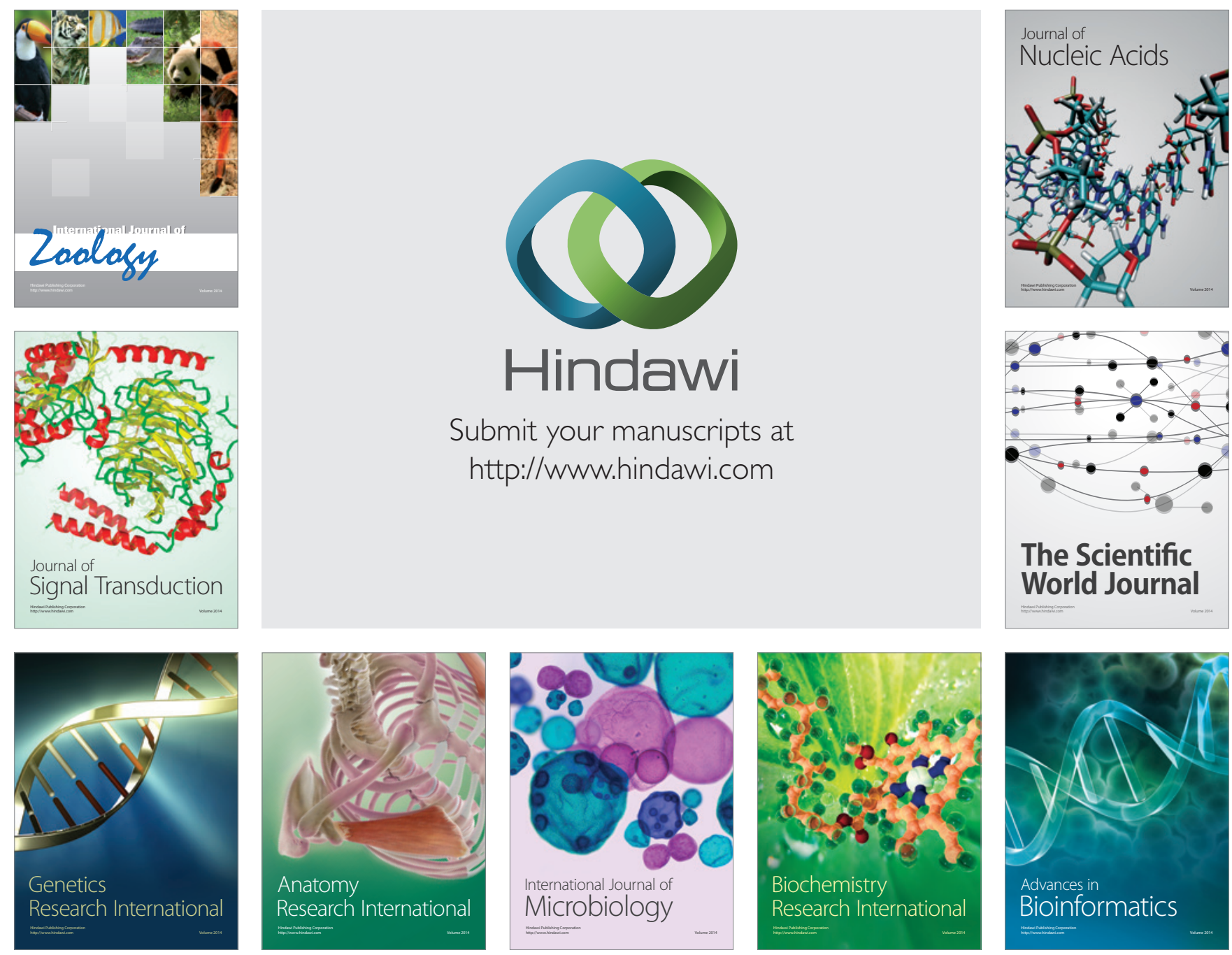

The Scientific World Journal
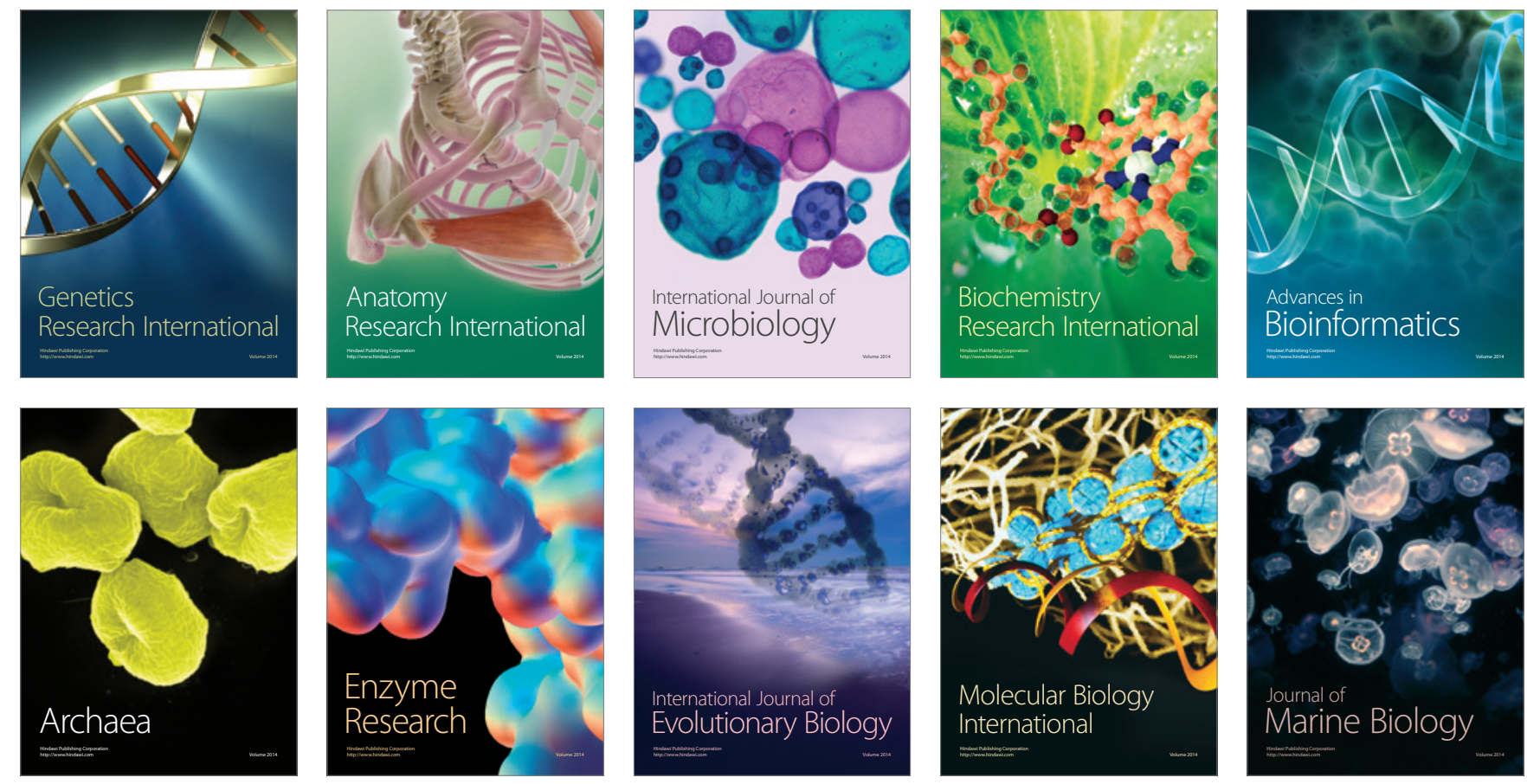